\title{
Stratospheric warming in Southern Hemisphere high latitudes since 1979
}

\author{
Y. $\mathrm{Hu}^{1}$ and Q. Fu ${ }^{2}$ \\ ${ }^{1}$ Department of Atmospheric Sciences, Peking University, Beijing, China \\ ${ }^{2}$ Department of Atmospheric Sciences, University of Washington, Seattle, USA
}

Received: 26 November 2008 - Published in Atmos. Chem. Phys. Discuss.: 16 January 2009

Revised: 17 June 2009 - Accepted: 22 June 2009 - Published: 3 July 2009

\begin{abstract}
In the present study, we show evidence of significant stratospheric warming over Southern Hemisphere high latitudes and large portions of the Antarctic polar region in winter and spring seasons, with a maximum warming of $7-8^{\circ} \mathrm{C}$ in September and October, using satellite Microwave Sounding Unit observations for 1979-2006. It is found that this warming is associated with increasing wave activity from the troposphere into the stratosphere, suggesting that the warming is caused by enhanced wave-driven adiabatic heating. We show that the stratospheric warming in Southern Hemisphere high latitudes has close correlations with sea surface temperature (SST) increases, and that general circulation model simulations forced with observed time-varying SSTs reproduce similar warming trend patterns in the Antarctic stratosphere. The simulated stratospheric warming is closely related to increasing wave activity in the Southern Hemisphere. These findings suggest that the stratospheric warming is likely induced by SST warming. As SST warming continues as a consequence of greenhouse gas increases due to anthropogenic activity, the stratospheric warming would also continue, which has important implications to the recovery of the Antarctic ozone hole.
\end{abstract}

\section{Introduction}

In the last quarter of the 20th century, one of the most dramatic changes in the stratosphere is severe ozone depletion in the Antarctic spring, i.e., the so-called Antarctic ozone hole.

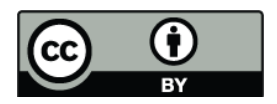

Correspondence to: $\mathrm{Y} . \mathrm{Hu}$

(yyhu@pku.edu.cn)
Associated with severe ozone depletion, the Antarctic stratosphere has displayed strong cooling trends in spring and summer between the late 1970s and the late 1990s (Solomon, 1999; Randel and Wu, 1999; Thompson and Solomon, 2002). It was generally thought that the strong cooling in the Antarctic stratosphere is mainly due to the radiative effect of severe ozone depletion (Ramaswamy et al., 1996; Ramaswamy et al., 2001). In addition, increasing greenhouse gases might also contribute to the observed cooling trends in the Antarctic stratosphere (Langematz et al., 2003; Shindell and Schmidt, 2004) due to their radiatively cooling effect on the stratosphere. The Antarctic stratospheric cooling trends may have important influences on the troposphere and surface climate through altering atmospheric circulations and waves. Indeed, Thompson and Solomon (2002) have linked the Antarctic stratospheric cooling to surface warming over the Antarctic Peninsula.

In contrast to the greatly emphasized Antarctic stratospheric cooling in austral spring and summer and its possible influences on tropospheric climate, here we report stratospheric warming over a large portion of the Southern Hemisphere (SH) high latitudes in austral winter and spring. Warming signals in the SH high-latitude stratosphere in austral spring were identified in previous studies (Ramaswamy et al., 1996; Randel and Wu, 1999; Johanson and Fu, 2007). However, little attention was paid to these warming trends. First, it is because conventional zonal and seasonal averages in these studies largely reduce magnitudes of warming trends. Second, these earlier studies focused on different interests. Ramaswamy et al. (1996) and Randel and Wu et al. (1999) were interested in the stratospheric cooling trends and their relationship with stratospheric ozone depletion. Johanson and $\mathrm{Fu}$ (2007) mainly focused on comparison of SH

Published by Copernicus Publications on behalf of the European Geosciences Union. 
temperature trends among satellite, radiosonde observations, and reanalysis datasets. One of our goals in this paper is to demonstrate that stratospheric warming trends in SH high latitudes have equal or greater magnitudes compared to cooling trends in austral spring, by showing the spatial pattern of temperature trends in individual months.

It is well known that polar stratospheric temperatures are determined by radiative and dynamical processes (Andrews, et al., 1987). The radiative effects of both ozone depletion and increasing greenhouse gases cause cooling in the stratosphere. Stratospheric aerosols, especially volcanic aerosols, absorb solar radiation and warm the stratosphere. However, it does not cause a decadal warming trend and cannot explain the spatial pattern as shown below. Thus, it is likely that the stratospheric warming in SH high latitudes is due to increasing wave activity. Planetary waves generated in the troposphere propagate upward and get into the stratosphere. Breaking of these waves causes convergence of wave fluxes, which acts as a driving force and causes poleward meridional circulation in the extratropical stratosphere, with upward motion in the tropics and downward motion in high latitudes (Holton et al., 1995). Downward motion causes adiabatic heating in the high-latitude or polar stratosphere because air parcels are compressed by larger pressure as altitude decreases. Therefore, whether wave activity has been increased in the past few decades has to be examined. In fact, both the Antarctic polar vortex and planetary wave activity in the SH stratosphere displayed very unusual dynamical behaviour in recent years. That is, the Antarctic stratospheric polar vortex appears to be more frequently and largely disturbed by planetary waves. For example, the unique sudden warming event occurred in the Antarctic in 2002 (Varotsos, 2004; Krüger et al., 2005, and articles in the same volume as the second paper), the vortex was very weak in 2004 due to strong wave activity, and the vortex broke down quite early in 2000 though the ozone hole of that year was anomalously large.

Our main goal in the present study is twofold. First, we document strong stratospheric warming trends in SH high latitudes using both satellite data and reanalysis, and examine whether the warming is caused by increasing wave activity in the SH stratosphere. Second, we explore whether the stratospheric warming is related to global greenhouse warming by carrying out general circulation model (GCM) simulations. Satellite and reanalysis datasets as well as model setup in this study are described in Sect. 2. In Sect. 3, we present linear trends in stratospheric temperatures derived from satellite and reanalysis data. We also examine the relationship between the stratospheric warming and EliassenPalm (EP) fluxes. In Sect. 4, we explore the impact of sea surface temperatures (SSTs) on the SH stratospheric warming with GCM simulations. Discussion and conclusions are presented in Sect. 5.

\section{Data and model setup}

To detect the Antarctic stratospheric temperature changes in the past few decades, we carry out linear trend analyses using two temperature datasets. The first dataset is 28 year (1979-2006) monthly temperature anomalies, which are departures from mean over the base period of 1979-1998, from satellite-borne Microwave Sounding Unit (MSU) channel $4\left(\mathrm{~T}_{4}\right)$ observations (Mears et al., 2003; Johanson and Fu, 2006, 2007). MSU T 4 measures microwave radiation emitted from the stratospheric layer between about 20 and $120 \mathrm{hPa}$, with a peak near $70 \mathrm{hPa}$ (Mears et al., 2003). The second dataset is 28-year (1979-2006) monthly temperatures from the National Center for Environmental Prediction/National Center for Atmospheric Research (NCEP/NCAR) reanalysis (Kalnay et al., 1996; Kistler et al., 2001). To calculate Eliassen-Palm (EP) fluxes (Andrews et al., 1987), we also use daily wind velocity and temperature data from NCEP/NCAR reanalysis. Student's t-test is used to test the statistical significance of trends. We use the $90 \%$ significance level (approximately corresponding to the t-test value of 1.7) as the standard for a trend to be statistically significant.

The model used here is the GCM developed at the Goddard Institute for Space Studies (GISS-modelE). The model has horizontal resolution of 4 by 5 degrees in latitude and longitude. It has 23 vertical layers from the surface up to $0.02 \mathrm{hPa}$ (about $80 \mathrm{~km}$ above the ground) with gravity-wave parameterizations for the stratosphere. A full description of the model, its performance and comparison with observational results can be found in Schmidt et al. (2006). Five ensemble members of simulations using different initial conditions were performed over 1950-2002, forced with observed time-varying sea surface temperatures (SST) (Rayner et al., 2003). To isolate the impact of SST warming on the SH stratosphere, ozone, greenhouse gas, and aerosol concentrations are all fixed at the 1950 level. Solar variability is not considered. Like most other GCMs, GISS-modelE is unable to produce the quasi-biennial oscillation in the tropical stratosphere.

\section{Trends in stratospheric temperatures and wave activ- ity}

Figure 1 shows the 28-year MSU $\mathrm{T}_{4}$ trends for $\mathrm{SH}$ high latitudes in austral winter and spring months. Warming trends occur in all these months. In June, July, and August, the warming trends are weak and statistically not significant. In September and October, the warming trends are strong and statistically significant, with maximum warming of $7-$ $8^{\circ} \mathrm{C}$ over the 28 years. In November, cooling trends are dominant, while warming trends are relatively week and not significant. The warming trends are not right over the polar cap, but centered at about $65^{\circ} \mathrm{S}$. The temperature trends show a wavenumber-1 like spatial pattern (a secondary 

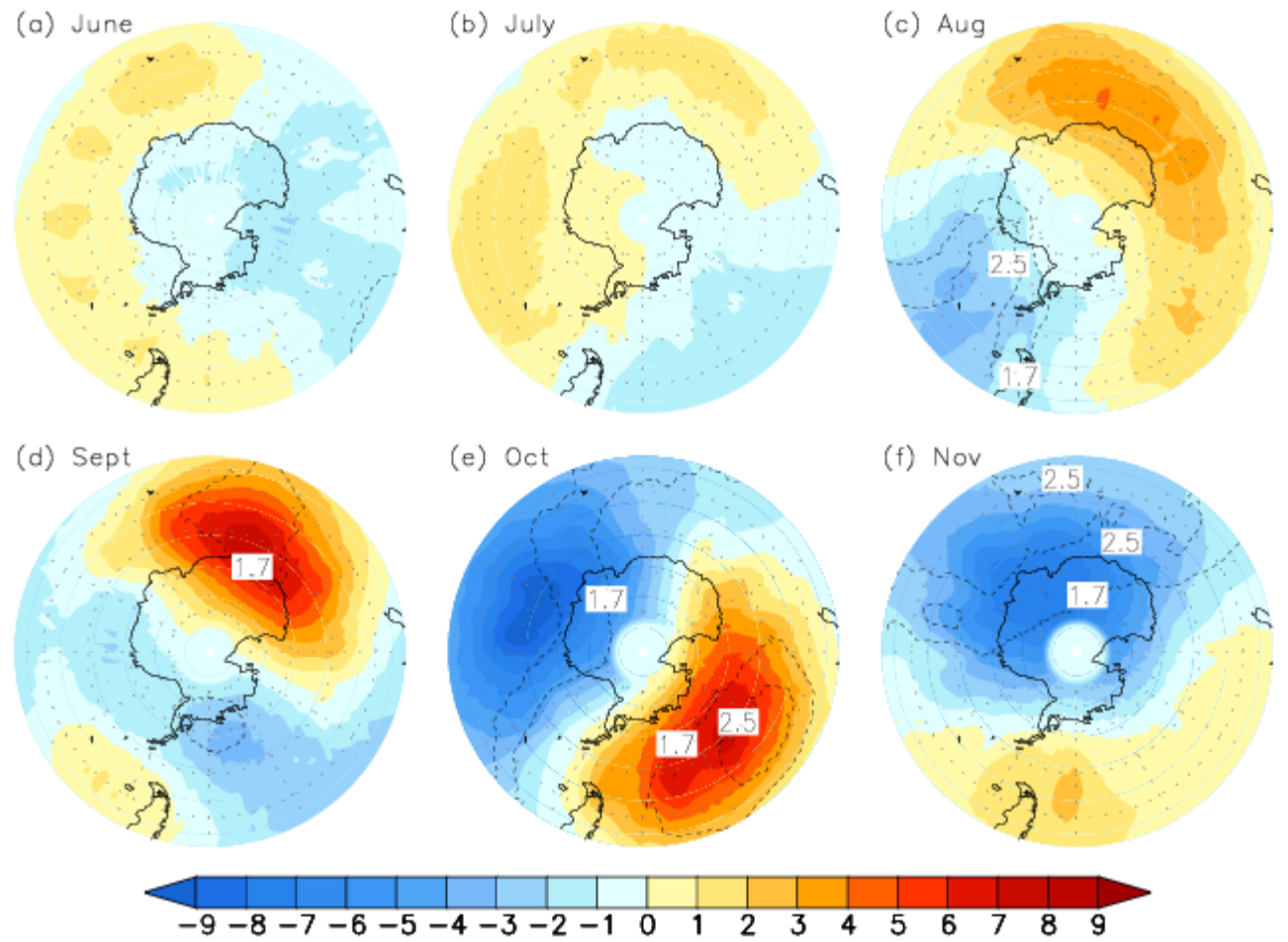

Fig. 1. Temperature trends in the lower stratosphere for 1979-2006 from satellite MSU channel $4\left(\mathrm{~T}_{4}\right)$ observations. $\mathrm{T}_{4}$ has a weighting function between about 20 and $120 \mathrm{hPa}$ and peaks at $\sim 70 \mathrm{hPa}$ ). The trends are shown from June to November. Color interval is $1^{\circ} \mathrm{C}$ per 28 years. Contours denote t-test values. For 28 years, student's t-test values 1.7 and 2.5 correspond to $90 \%$ and $98 \%$ confidence levels, respectively.

wavenumber-2 pattern can also be identified in September), with eastward shifting in these months. The warming area in September matches the climatological location of high temperatures in the SH stratosphere in austral winter and spring. The spatial pattern in October resembles minor sudden warmings in the Arctic stratosphere (Krüger et al., 2005). It suggests a tendency of the polar vortex shifting off the polar cap. The cooling trends, especially those in October and November, are due to Antarctic ozone depletion, as pointed out in many previous studies (Ramaswamy et al., 1996; Randel and Wu, 1999; Solomon, 1999 among others). It is noticed that the stratospheric sudden warming in 2002 has an important contribution to the warming trends in September and October (Varotsos, 2004; Krüger et al., 2005). However, the maximum warming trends are still up to $5-6^{\circ} \mathrm{C}$ even if the 2002 warming is excluded, and the spatial trend pattern remains the same (see Fig. 2).

From Fig. 1d, one can find that warming trends are dominant over SH high latitudes, and that the magnitudes of warming trends are much larger than that of cooling trends. However, zonal average would largely reduce the warming magnitude in September. For October (Fig. 1e), warming trends take nearly half of the SH high-latitude area and have almost equal magnitudes to that of cooling trends (the maximum warming is slightly weaker than the maximum cool- (a) Sept

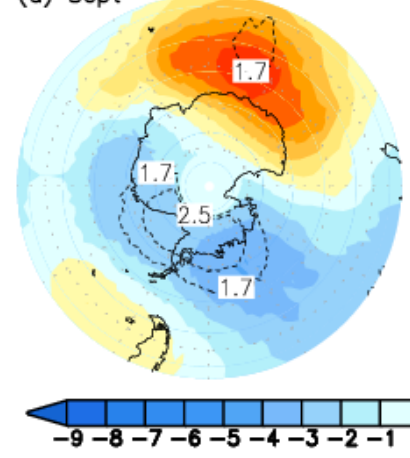

Fig. 2. Same as Fig. 1d and e, except for that year 2002 is excluded.

ing). Zonal average would lead to weak cooling trends in this month (see Fig. 8 in Randel and Wu (1999), which showed zonal-mean temperature trends over 1979-1997 using MSU $\mathrm{T}_{4}$ ). Due to the strong cooling in November and mismatch of locations of warming trends in September and October, conventional seasonal average over the three months yields a maximum warming of about $2.5^{\circ} \mathrm{C}$ over the 28 years (see Fig. 2 in Johanson and Fu, 2007). 

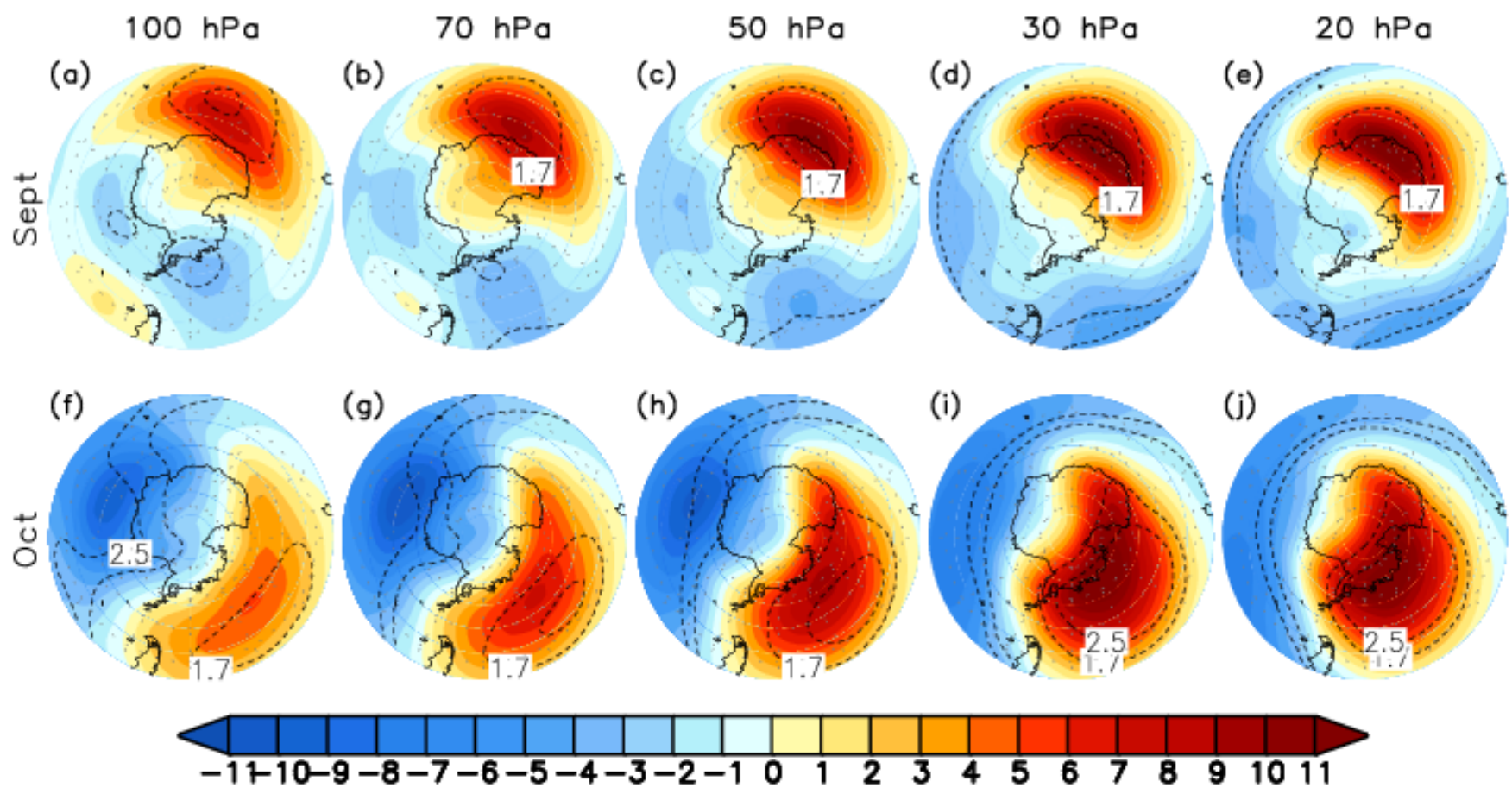

Fig. 3. 28-year (1979-2006) temperature trends for September (top) and October (bottom) at stratospheric levels, derived from NCEP/NCAR reanalysis. Color interval is $1^{\circ} \mathrm{C}$ per 28 years. Contours denote student's t-test values.

For comparison, temperature trends at different stratospheric levels in SH are also calculated from NCEP/NCAR reanalysis. It is found that the trends from NCEP/NCAR reanalysis match satellite-inferred MSU $\mathrm{T}_{4}$ trends exceptionally well in both spatial patterns and magnitudes in all winter and spring months. To focus on strong warming trends, we only show results for September and October in Fig. 3. For both months, warming trends are found at all stratospheric layers in the reanalysis data. The spatial patterns of warming trends are similar at these levels. Warming magnitudes increase with altitudes and reach the maximum value of about $11^{\circ} \mathrm{C}$ at $30 \mathrm{hPa}$. At $70 \mathrm{hPa}$, the maximum warming for both months is greater than $7^{\circ} \mathrm{C}$ (see Fig. $3 \mathrm{~b}$ and g). One can find that the spatial patterns of warming trends tilt toward the pole with increasing altitudes. In particular, more than half of the polar region is dominated by warming trends in October. Again, the 2002 sudden warming does not affect the results (results not shown).

Stratospheric warming in SH high latitudes are also reflected in changes of geopotential height because warming at a layer must lead to an increase in geopotential height aloft. To demonstrate this, we plot trends in geopotential heights at stratospheric levels for September and October (Fig. 4). The spatial patterns are similar to that of temperature trends. Magnitudes of geopotential height trends increase with altitudes. At $20 \mathrm{hPa}$, the maximum positive trends for both months are greater than $600 \mathrm{~m}$. The positive trends in September are stronger than in October. The center of positive trends also show tilting toward the pole as altitude increases, similar to that of temperature trends.

It is likely that the stratospheric warming has direct linkage with the warming in the Antarctic troposphere in winter and spring, derived from both radiosonde data (Turner et al., 2004) and MSU data (Johanson and Fu, 2007). The tropospheric warming trends in austral spring, which are weaker compared to the stratospheric warming, are also mainly over the eastern side of the Antarctic continent (Johanson and Fu, 2007), consistent with the locations of stratospheric warming trends. At current stage, we are unaware how the warming trends are linked between the stratosphere and troposphere.

The stratospheric warming shown above cannot be explained by radiative effects of increasing greenhouse gases and ozone depletion. It is because increasing greenhouse gases in the atmosphere leads to surface and tropospheric warming but stratospheric cooling. Ozone depletion during the past few decades has also contributed to stratospheric cooling, especially in the Antarctic lower stratosphere in spring and summer.

It is well known that polar stratospheric temperatures are also crucially determined by planetary-scale waves that are generated in the troposphere (Andrews et al., 1987). As planetary waves propagate upward into the stratosphere, breaking of these waves drives a meridional residual circulation with rising motion in the tropics, poleward flow at mid-latitudes, and downward motion in polar regions (i.e., "Brewer-Dobson circulation"). The polar stratospheric temperature is thus 

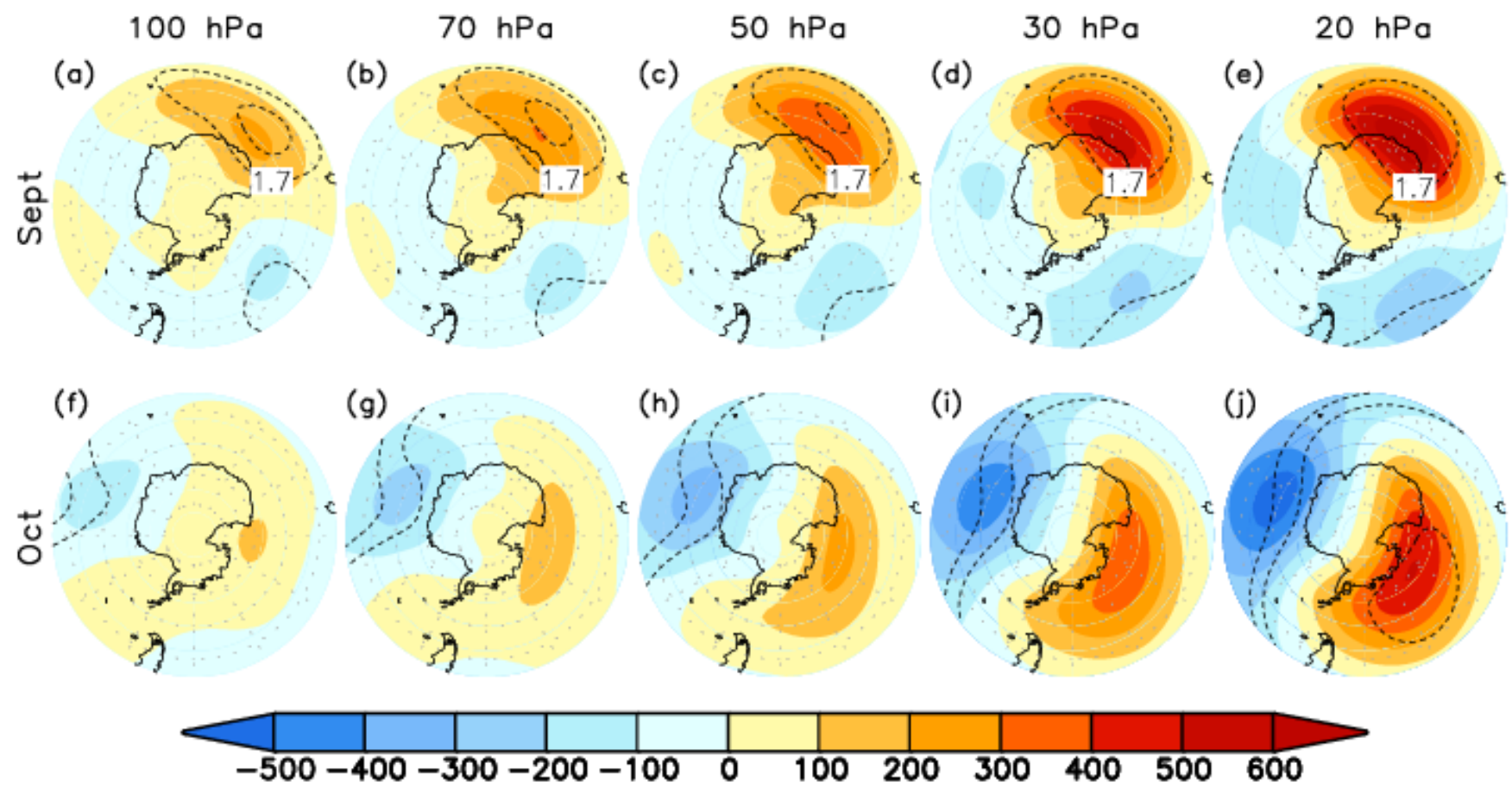

Fig. 4. Same as Fig. 3, except for trends in geopotential heights. Color interval is 100 geopotential meters per 28 years.

determined by a balance between radiative cooling and dynamic heating from induced vertical motion due to planetary wave dissipation. Therefore, the observed stratospheric warming is likely caused by increased wave activity from the troposphere into the stratosphere. The remarkable agreement of warming trends between MSU $\mathrm{T}_{4}$ and NCEP/NCAR reanalysis allows us to use the reanalysis to examine decadal changes in wave activity.

To show how changes in wave fluxes cause the strong warming over the SH high-latitude stratosphere in September and October, we plot the 28-year trends in EP flux vectors (arrows) and EP flux divergence (colors) averaged over August-September-October (ASO) in Fig. 5, using NCEP/NCAR reanalysis. We include EP fluxes in August because wave fluxes in the previous month also contribute to dynamical heating in the month considered ( $\mathrm{Hu}$ and Tung, 2002). The direction of arrows represents the tendency of wave propagation over 1979-2006. Arrows are generally upward between $50^{\circ} \mathrm{S}$ and $90^{\circ} \mathrm{S}$, indicating enhanced wave fluxes from the troposphere into the stratosphere. Arrows from the upper troposphere to the stratosphere between $30^{\circ} \mathrm{S}-50^{\circ} \mathrm{S}$ are equatorward, suggesting enhanced equatorward wave propagation. EP flux divergence show negative trends in the stratosphere and upper troposphere between about $45^{\circ} \mathrm{S}$ and $70^{\circ} \mathrm{S}$. The negative trends indicate enhanced EP flux convergence in these regions. The significant enhancement of EP flux convergence in the stratosphere suggests an intensified Brewer-Dobson circulation and thus enhanced dynamical heating in the polar stratosphere. On the other hand, EP flux divergence shows strong positive trends in the middle troposphere between about $30^{\circ} \mathrm{S}$ and $70^{\circ} \mathrm{S}$. The positive trends are indicative of increased wave activity generation.

To quantitatively show increases of wave fluxes in the stratosphere for August, September and October, respectively, in Fig. 6 we plot the time series of total eddyheat fluxes at $30 \mathrm{hPa}$ in middle and high latitudes for these months. Here, eddy-heat flux is equivalent to the vertical component of EP fluxes. For all three months, eddy-heat fluxes show increases over the 28 years. For August and September, the trends in eddy-heat fluxes are strong and statistically significant, with net increases of $48.4 \%$ and $42.1 \%$, respectively. For October, the trend is relatively weak and not significant, with a net increase of $10 \%$. Calculations of eddyheat fluxes are done for June and July. It shows very weak increases of less than $10 \%$. Similar results are also found at other stratospheric levels.

Changes in eddy-heat fluxes have close correlation with temperatures in the warming area. Figure 7a shows the time series of eddy-heat fluxes at $30 \mathrm{hPa}$, averaged over August and September (solid straight line). Superimposed on the plot is the time series of MSU $\mathrm{T}_{4}$ temperature for September, averaged over the area within which warming trends are larger than $6 \mathrm{~K}$ for the 28 years (dashed-line). The averaged eddy-heat fluxes have significant positive trend, with a net increase of $45 \%$. Correlation coefficient between the two is about 0.8. Note that heat flux in July is not included in calculating the correlation coefficient because it has a very 


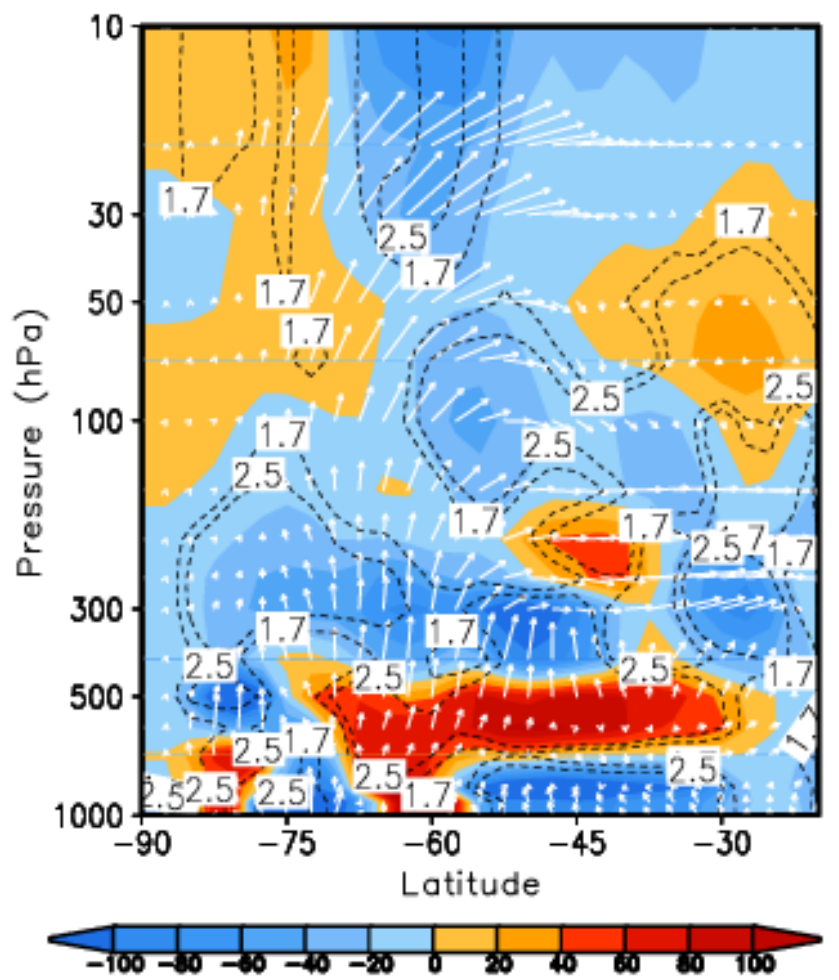

Fig. 5. 28-year trends in EP fluxes and EP flux divergence averaged over August-September-October and derived from NCEP/NCAR reanalysis. Arrows, color shading, and dashed contours indicate trends in EP flux vectors, EP flux divergence, and student's t-test values. To show the trends at higher levels, EP flux vectors are divided by the background air density. The scale length of arrows, $1 \mathrm{~cm}$, represents $1.0 \times 10^{8} \mathrm{~m}^{3} \mathrm{~s}^{-2}$ per 28 years. Because the vertical component of EP fluxes is about two orders smaller than the horizontal component, the vertical component is multiplied by 100 to display changes in EP flux vectors in the vertical direction. Trends in EP flux divergence are shown with a color interval of $20 \mathrm{~m}^{2} \mathrm{~s}^{-2}$ per 28 years, with blue colors for negative trends (enhanced EP flux convergence) and yellow-red colors for positive trends (enhanced EP flux divergence).

weak and insignificant trend. Figure $7 \mathrm{~b}$ shows the time series of eddy-heat fluxes at $30 \mathrm{hPa}$, averaged over AugustSeptember-October, and averaged MSU $\mathrm{T}_{4}$ temperature for October. Over the three months, the averaged eddy-heat fluxes also show a significant positive trend, with a net increase of $30 \%$ over the 28 years. The correlation between eddy-heat fluxes and temperature is about 0.4. Though the correlation coefficient is much lower than that in Fig. 7a, its statistical significance is above the $90 \%$ significance level. The close correlation suggests that the observed stratospheric warming is caused by wave-driven dynamical heating.

The much stronger warming in September and October than in other months coincides with the seasonality of the planetary wave activity in the SH stratosphere. From Fig. 6, one can find that eddy-heat fluxes in September and Octo-
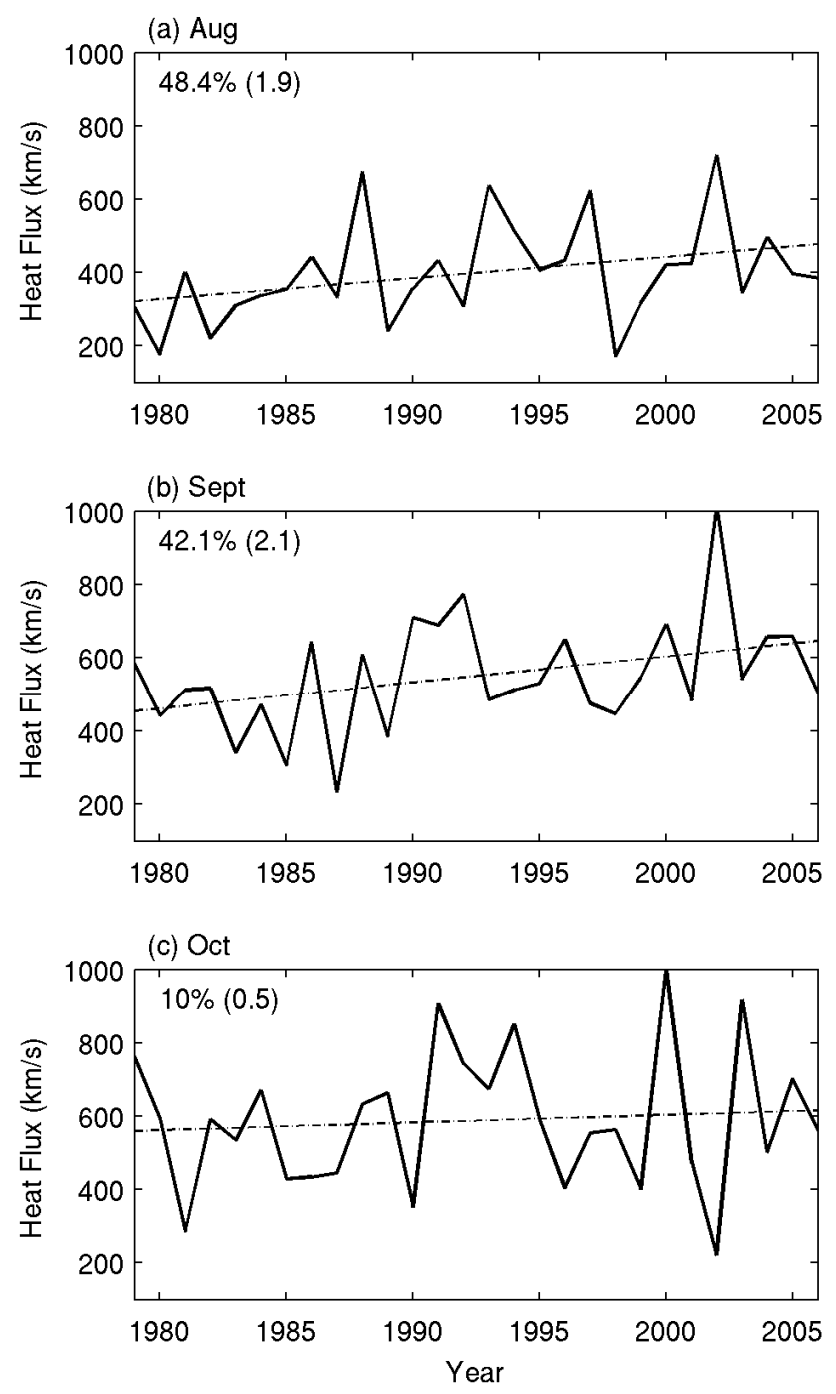

Fig. 6. Time series of total eddy-heat fluxes at $30 \mathrm{hPa}$, areaweighted between $90^{\circ} \mathrm{S}$ and $40^{\circ} \mathrm{S}$, for August (a), September (b) and October (c), derived from NCEP/NCAR reanalysis. Solid line is the time series of eddy-heat fluxes, and dashed-line denotes the linear regression. Marked values are the net increases in eddy-heat fluxes over the 28 years (percentages) and student's t-test (t). In calculating eddy-heat flux, we use potential temperature, rather than temperature.

ber are much larger than that in August. The average values of eddy-heat fluxes over the 28 years are about 400, 550, and $600 \mathrm{~K} \mathrm{~m} / \mathrm{s}$ for August, September, and October, respectively. This is consistent with the results in previous observational results (Randel, 1988), which showed that the amplitudes of wavenumber 1 and 2 reach the maxima in September and October in the SH stratosphere. It is because the strong polar night jet suppresses upward propagation of planetary waves in winter months (e.g., June, July, and August) and easterly winds in summer months tend to prevent upward propagation of planetary waves. It suggests that enhanced 

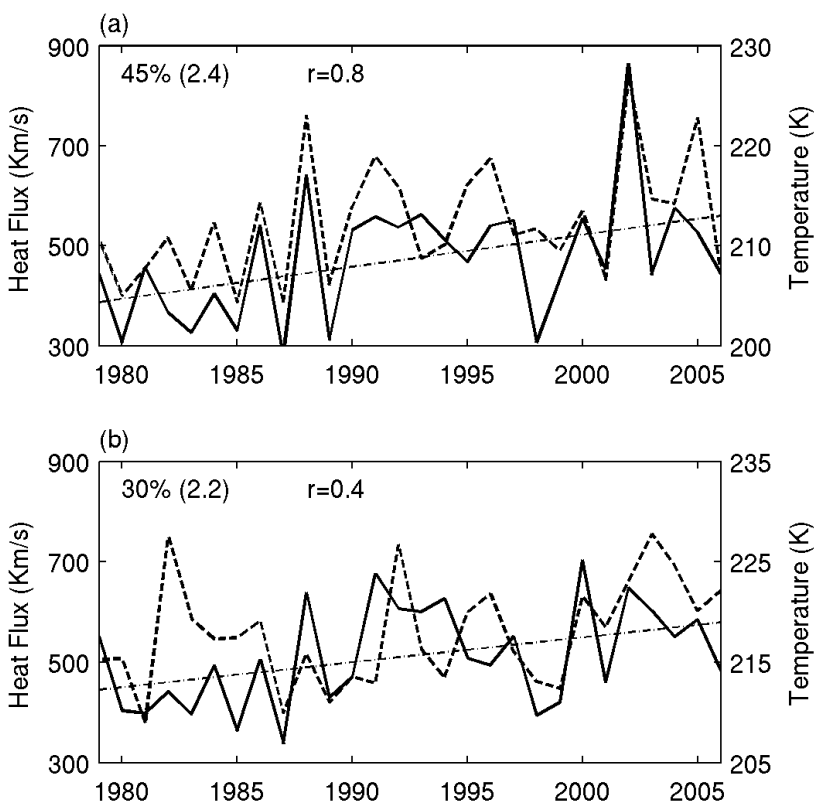

Fig. 7. Time series of total eddy-heat fluxes at $30 \mathrm{hPa}$ from NCEP/NCAR reanalysis (solid line) and averaged temperatures in the warming area enclosed by the contour of $6^{\circ} \mathrm{C}$ per 28 years from $\mathrm{MSU} \mathrm{T}_{4}$ (dashed-line). In plot (a), eddy-heat fluxes are averaged over August and September, and the averaged temperature is for September. In plot (b), eddy-heat fluxes are averaged over AugustSeptember-October, and the averaged temperature is for October. In both plots, the dashed-dotted straight line is the linear regression for eddy-heat fluxes. Values marked in the plots are the net increase in eddy-heat fluxes over the 28 years (percentages), student's t-test values (in brackets), and correlation coefficients between temperature and eddy heat fluxes $(r)$.

wave-driven adiabatic heating is more significant in the period when planetary wave activity is strong. Though the increase in wave fluxes in October is relatively weak, strong increases in wave fluxes in September and August contribute largely to the warming in October.

An important feature in Fig. 1 is the eastward shifting of the warming trend pattern, especially the shifting between September and October. One possible explanation is that the shifting might be related to the increase in the wave activity of travelling planetary waves, which have nearly equal amplitudes to that of stationary waves. To examine this, we separate stratospheric eddy-heat fluxes into two parts: travelling and stationary wave fluxes, following Randel (1988). It is found that travelling wave fluxes have only a relatively weak increase, less than $10 \%$ (figure not shown). This weak increase can hardly explain the strong warming in October and its eastward shifting. In a very recent work by Lin et al. (2009), they showed that the eastward shifting of warming trend pattern between September and October is due to a phase shift of climatological-mean center of high temperatures in the SH stratosphere in October in the past few decades. They found that the effect of the phase shift can

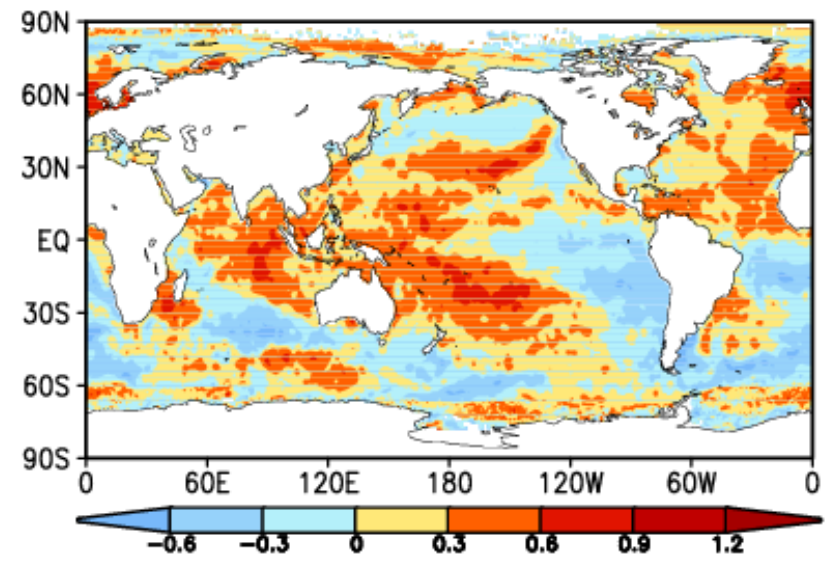

Fig. 8. Relationship between stratospheric warming and global SST changes in September. Correlation coefficients between a basepoint temperature of MSU $\mathrm{T}_{4}$, averaged over the area enclosed by the contour of $6^{\circ} \mathrm{C}$ per 28 years, and global observed SST over 1979-2006. Color interval is 0.3 . In calculating the correlation coefficients, a 3.5-year filter is used to remove high-frequency variations in both SST and MSU T 4 . For 28 years, correlation coefficient of 0.3 approximately marks the $90 \%$ significance level.

account for $84 \%$ of the observed temperature trends in October. The reason that caused such a shift of the climatologicalmean spatial pattern of stratospheric temperatures remains an open question.

Increasing wave fluxes in the middle and high-latitude stratosphere would also cause more ozone to be transported from low to high latitudes (Fusco and Salby, 1999; Fischer et al., 2008). Because the polar night jet tends to block air transport across the polar vortex edge, ozone-rich air is accumulated outside the polar vortex. Thus, enhanced wave flux convergence leads to more ozone accumulation outside the polar vortex, which may also contribute to the observed warming by absorbing more ultraviolet radiation. To examine this, we calculate the trends in total ozone using the satellite Total Ozone Mapping Spectrometer/Solar Backscatter Ultraviolet observations. A weak ozone increase of 5-6 Dobson Units for 1979-2006 is found in the warming areas in September and October (figure not shown), which is too small to explain the observed warming radiatively.

\section{Simulations with SST forcing}

An important question is what causes the increased planetary wave activity. Early studies suggested that changes in SSTs might lead to changes in SH wave activity, which consequently modulate SH atmospheric circulations (Hurrell and Loon, 1994). Recent studies on the 2002 Antarctic major warming showed that strong wave activity originated from the tropical troposphere (Nishii and Nakamura, 2004). In modelling studies of SST influences on the North 

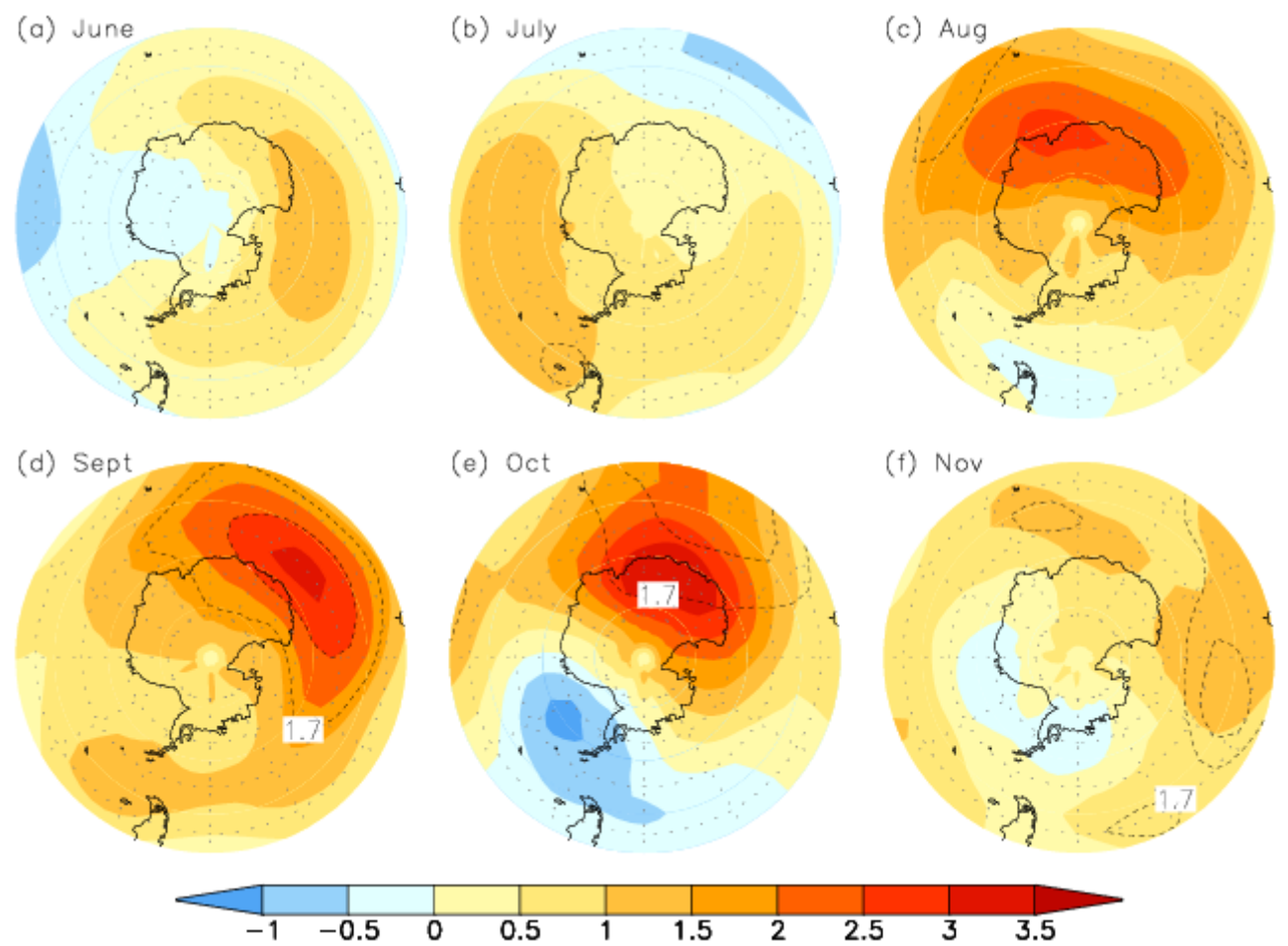

Fig. 9. Temperature trends at $70 \mathrm{hPa}$ from GCM simulations. The trends are shown from June to November, derived from 5-ensemble simulations. Color interval is $0.5^{\circ} \mathrm{C}$ per 24 years. Contours denote t-test values.

Atlantic oscillation (NAO), Hoerling et al. (2001) pointed out that the decadal trends of NAO are originated from tropical SST warming. Studies by Hoerling et al. (2004) and Lau et al. $(2005,2006)$ further suggested that tropical SST warming in the region of Indian and Western Pacific oceans plays the major role in forcing extratropical tropospheric changes. Therefore, a plausible mechanism responsible for the increasing wave activity and the observed stratospheric warming is SST changes.

To verify the relationship between the stratospheric warming and SST changes, we first examine the correlation of the $\mathrm{MSU} \mathrm{T}_{4}$ in September, averaged over the warming area enclosed by the contour of $6^{\circ} \mathrm{C}$ per 28 years, with observed global SST (Rayner et al., 2003) for 1979-2006. Figure 8a shows the spatial distribution of correlation coefficients in September. Significant correlations are found mainly over the Tropical Indian Ocean and Western Pacific warm pool regions, Southern and Northern Extratropical Pacific, and Northern Subtropical Atlantic. Correlation between stratospheric temperatures in NCEP/NCAR reanalysis and SST has nearly the same spatial pattern. All these areas show relatively large SST warming trends (Lau et al., 2006). It suggests that the stratospheric warming is largely related to SST warming.

To examine whether the high-latitude stratospheric warming is a response to SST warming, we carry out GCM simulations with prescribed SST and sea ice, using GISS-modelE.
Five ensemble members of simulations were performed over 1950-2002, forced with observed monthly time-varying SST (Rayner et al., 2003). Ozone, well-mixed greenhouse gas concentrations, and all other atmospheric compositions are fixed at the 1950 level to isolate the impact of time-varying SST. Figure 9 shows the trends in ensemble-mean monthly temperatures from GCM simulations at $70 \mathrm{hPa}$ for $1979-$ 2002. Warming trends are found over the Antarctic in all winter and spring months, with strong warming in ASO. The lack of stratospheric cooling in GCM simulations (as compared with observations) is because ozone depletion and increasing greenhouse gases are not included in the simulations. The spatial distribution of simulated temperature trends show a wavenumber-1 pattern, with eastward shifting (A secondary wavenumber-2 pattern can also be seen in Fig. 9). The locations of simulated maximum warming trends in August and September match observations very well, while that in October does not due to the lack of eastward shifting. The ensemble-mean maximum warming trend occurs in September and October, which is about $3.5^{\circ} \mathrm{C}$ over 1979-2002. In June, July, and November, the warming trends are relatively weak, about $1.0^{\circ} \mathrm{C}$ for the 24 years. It appears that the seasonality of the simulated warming trends is consistent with observations. Compared with MSU $\mathrm{T}_{4}$ trends (about $0.29^{\circ} \mathrm{C}$ per decade), the simulated warming trends are weaker (about $0.15^{\circ} \mathrm{C}$ per decade), which is about half in magnitudes. However, individual simulations show 


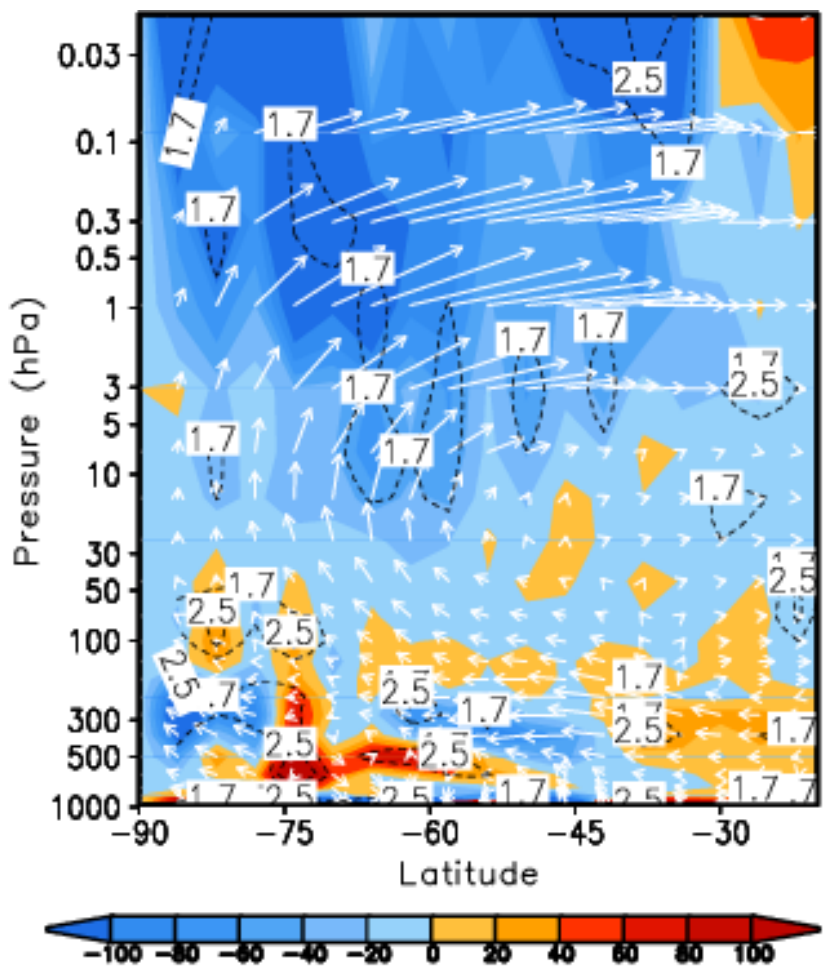

Fig. 10. Same as Fig. 5, except for simulated EP flux trends over 24 years (1979-2002).

more realistic warming trends. For example, the maximum warming can be as large as about $6^{\circ} \mathrm{C}$ over the 24 years in individual simulations. It is found that the reduction of the warming in ensemble mean is largely because of the location mismatch of maximum warming trends between individual simulations.

To demonstrate whether the simulated stratospheric warming in SH high latitudes is related to increasing wave fluxes, we show the trends in simulated EP flux vectors and EP flux divergence (see Fig. 10). Similar to that in Fig. 5, the arrows are generally upward at high latitudes in both the troposphere and the stratosphere, and the stratosphere and mesosphere all show enhanced convergence of EP fluxes (i.e., negative trends in EP flux divergence). These suggest that the simulated stratospheric warming is indeed related to increasing wave fluxes due to SST forcing. The differences from Fig. 5 are: the length of the arrows in the stratosphere is much shorter (note that both have the same scale length), and the arrows in the middle and low-latitude upper troposphere are poleward, rather than equatorward. The former suggests smaller increase in wave fluxes, which may explain the weaker warming in simulations. The latter is indicative of that increasing wave activity is originated from the tropics.

Figure 11 shows time series of simulated total eddy-heat fluxes at $30 \mathrm{hPa}$ and in middle and high latitudes for August, September, and October. The positive trend for August is
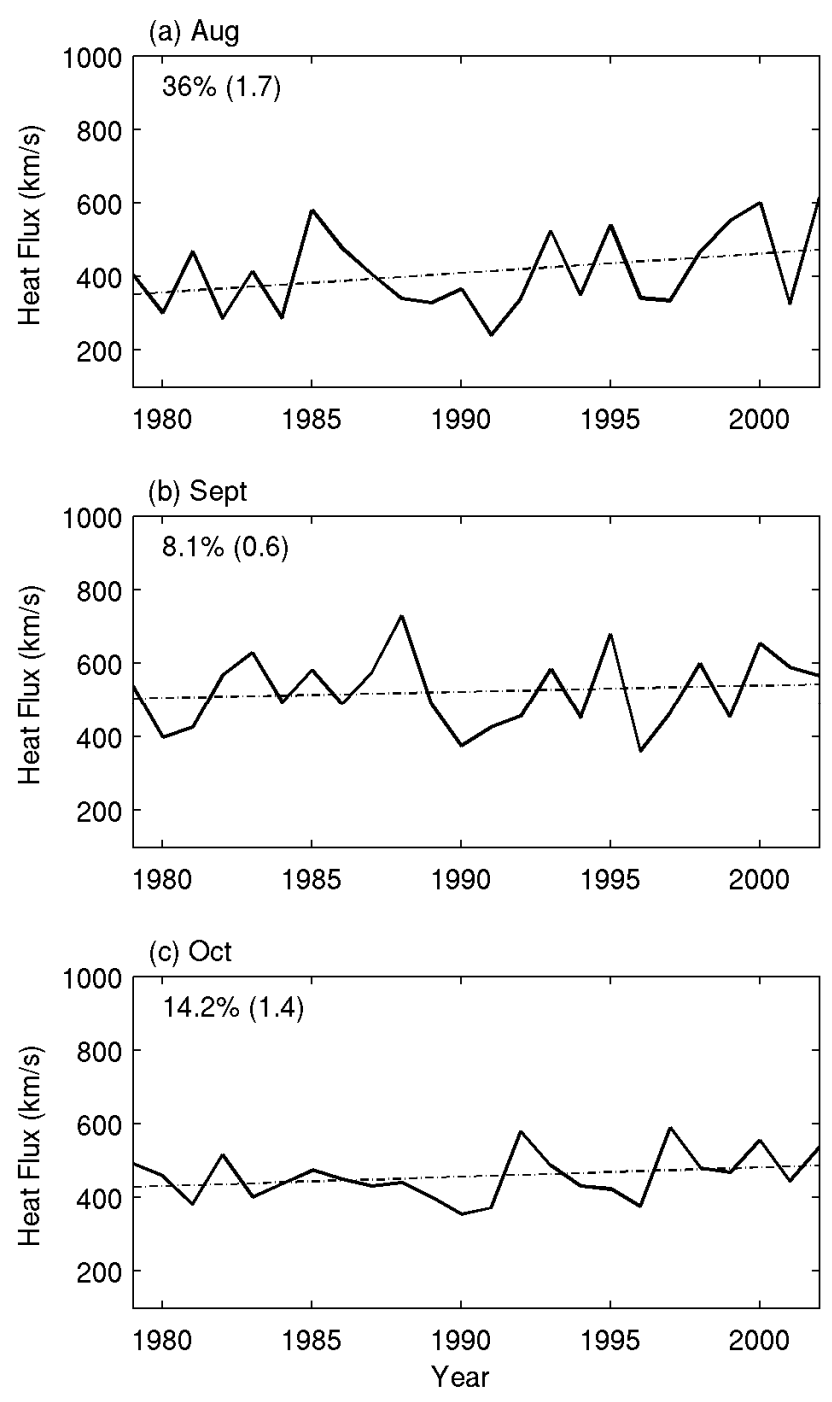

Fig. 11. Same as Fig. 6, except for simulated eddy-heat fluxes at $30 \mathrm{hPa}$.

strong and significant, with a net increase of $34.5 \%$ over 24 years, while the trends for September and October are relatively weak and statistically not significant. The net increases of eddy-heat fluxes are $7.8 \%$ and $13.6 \%$ for September and October, respectively. Compared with that in Fig. 5, the simulated eddy-heat flux increases are much smaller. This again explains why the simulated warming trends are weaker than observations.

Figure 12a shows time series of averaged total eddy-heat fluxes over August and September (solid line) and September temperature at $70 \mathrm{hPa}$, averaged in the warming area. The correlation coefficient between them is as high as 0.9 . The averaged increase of eddy-heat flux over the two months is $19 \%$, about half of that in reanalysis. Figure $12 \mathrm{~b}$ shows time series of averaged total eddy-heat flux over ASO and October temperature at $70 \mathrm{hPa}$, averaged in the warming area. The 

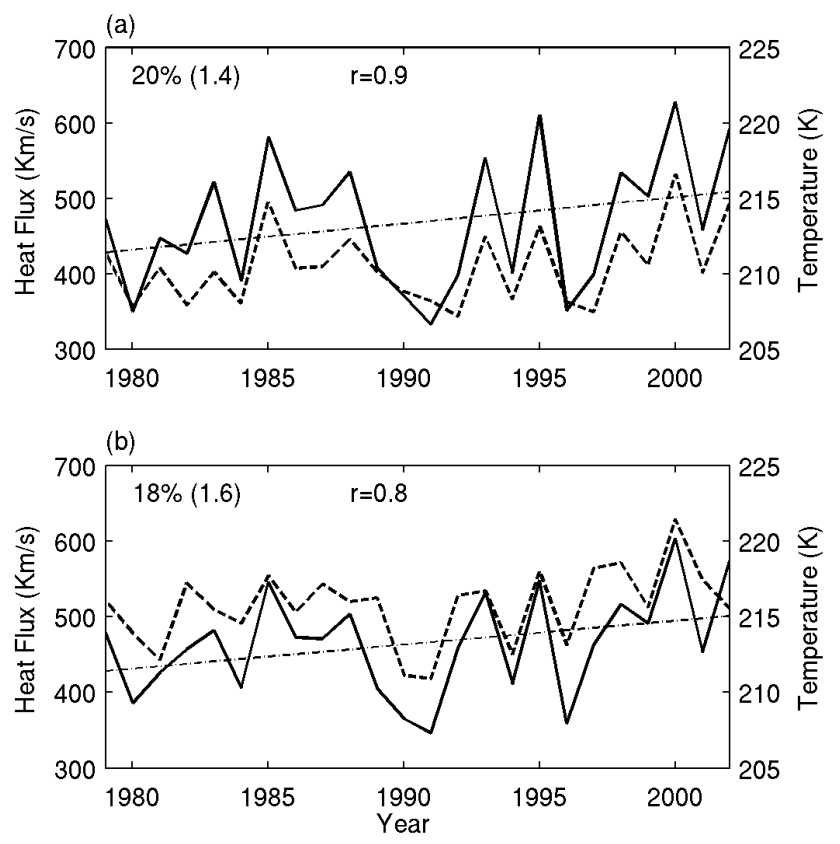

Fig. 12. Same as Fig. 7, except for simulated eddy-heat fluxes and temperatures. The averaged temperature is within the warming area enclosed by the contour of $2.5^{\circ} \mathrm{C}$ per 24 years.

correlation coefficient between them is high as well (about 0.8). Because simulations do not show eastward shift of warming trends in October, the warming in October is mainly caused by increasing wave activity, and it thus has a much higher correlation compared to that in reanalysis.

\section{Discussion and conclusions}

We have shown that the SH high-latitude stratosphere has been warming in winter and spring months since 1979. The warming trends are particularly strong in September and October, and warming magnitude is equal to that of cooling trends. Results from MSU $\mathrm{T}_{4}$ data show that the maximum warming in the two months is as large as $7-8^{\circ} \mathrm{C}$ over 1979-2006. In NCEP/NCAR reanalysis, warming trends are found at all stratospheric levels, and the maximum warming is about $11^{\circ} \mathrm{C}$ at 30 and $20 \mathrm{hPa}$. The spatial distributions of temperature trends show a wavenumber-1 like pattern, shifting eastward. In September and October, warming trends are located over the eastern side of the Antarctic continent, and warming centers tilts toward the pole as altitude increases.

The stratospheric warming is closely related to increasing wave fluxes in the SH stratosphere. Our calculations show significant increased EP fluxes and enhanced EP flux convergence in the extratropical stratosphere. The enhancement of EP flux convergence leads to intensified residual meridional circulation and thus stronger downward motion in $\mathrm{SH}$ high latitudes, which causes enhanced adiabatic heating. These suggest that the warming is due to enhanced wave-driven dynamical heating. Warming trends are also found in the Arctic stratosphere in boreal early winter months (November and December) (Hu et al., 2005). They showed that the Arctic stratospheric warming is also closely related to increasing wave fluxes in the Northern Hemisphere.

The close correlation between stratospheric temperatures in the warming region and SST suggests that the stratospheric warming is connected to SST warming. GCM simulations forced by observed time-varying SST can reasonably reproduce the seasonality and spatial patterns of observed warming trends. The simulations also show increasing wave activity in the stratosphere. Using different GCM simulation datasets, Hu and Pan (2009) showed that the observed warming in the stratospheric Arctic in $\mathrm{Hu}$ et al. (2005) can also be reproduced by SST forcing. The shortcoming of the simulations is that the magnitude of ensemble-mean warming trends is about half of observations. The weaker warming is consistent with the weaker increase in wave activity, which is also about half of observations. Because SST warming is due to increasing greenhouse gases (Knutson and Manabe, 1998; IPCC, 2007), the SH high-latitude stratospheric warming is an integral part of global greenhouse warming.

Previous studies suggested that tropical SST warming, especially SST warming over tropical Indian and western $\mathrm{Pa}-$ cific oceans, plays a major role in forcing changes on atmospheric waves and circulations in the extratropics through remote atmospheric connections (Hoerling et al., 2001, 2004; Lau et al., 2005, 2006). These works mainly focused on extratropical responses on tropical SST warming in the troposphere. Our simulation results indeed show increasing wave fluxes originated from the tropospheric tropics (Fig. 10). While our simulation result is consistent with the argument in previous studies, it is different from EP flux vector trends in reanalysis, which suggest a source of increasing wave activity in the extratropical troposphere. How SST warming causes increasing wave activity in both the extratropical troposphere and stratosphere and how is the relative importance of tropical SST warming need further investigations in future simulation works. In addition, the ensemble-mean simulation results shown here are mainly for comparison with observations. We plan to carry out detailed analyses on the simulation results, including vertical structures of the simulated warming trends, inter-ensemble variability of trends, and comparison with simulations forced by climatological SSTs.

In the present study, we have only tested SST forcing on wave activity and stratospheric warming in SH high latitudes. Other external forcing, such as increasing greenhouse gases and ozone depletion through their impact on stratospheric cooling, solar variability, aerosols and others, may also have important influences on increasing wave activity through altering atmospheric thermal structures. It is known that the increase of greenhouse gases is largely responsible for the warming trends in SST and its coupled 
tropospheric temperatures during the last three decades. Using a simple GCM, Eichelberger and Hartmann (2005) have shown that increasing greenhouse gases alone can cause increasing wave activity and an intensified Brewer-Dobson circulation, implying stratospheric polar warming. They found that the increase in wave activity is caused by sharper temperature contrast between the tropics and extratropics, with stronger warming in the upper tropical troposphere and weaker warming in higher latitudes. The sharper temperature contrast causes stronger baroclinic waves and consequently leads to increasing activity in synoptic and planetary waves. Butchart and Scaife (2001) and Butchart et al. (2006) also showed intensification of the Brewer-Dobson circulation in full atmospheric GCM simulations forced by both increasing greenhouse gases and time-varying SSTs. However, coupled atmosphere-ocean GCM simulations for the Intergovernmental Panel on Climate Change Fourth Assessment Report failed to reproduce the observed high-latitude stratospheric warming, as pointed out by Lin et al. (2009). In addition, El Nino and Southern Oscillation may also contribute to the interannual variability of the observed temperatures, which needs to be considered in future studies.

The observed strong stratospheric warming in September and October may have important implications for ozone-hole recovery because the Antarctic ozone hole mainly occurs in those two months. It is well understood that extremely low temperatures in Antarctic winter and spring are one of the critical conditions for severe ozone depletion and the formation of the Antarctic ozone hole (Solomon, 1999). Low polar temperatures lead to the formation of polar stratospheric clouds (PSC), on which heterogeneous chemical reactions involving man-made chlorine take place and result in rapid ozone depletion. The cold conditions also cause the strong Antarctic vortex that provides an isolated environment for polar ozone depletion (McIntyre, 1989). As SST warming continues as a consequence of increasing greenhouse gases, stratospheric warming in SH high latitudes will also continue. Although the warming area is not right over the polar cap, the warming may reduce PSC formation in part of the Antarctic polar region, which slows down heterogeneous chemical reaction rates. Consequently, the warming would cause reduction of the severity and duration of the Antarctic ozone hole. Moreover, the associated increasing wave activity in the SH stratosphere would also cause the Antarctic polar vortex weakened and more ozone transported into the polar region from low latitudes. These will all benefit the recovery of the Antarctic ozone hole, in addition to the decline of ozone depleting substances (Weatherhead and Andersen, 2006; WMO, 2007).

Acknowledgements. Y. Hu is supported by grants from the NSF of China (40575031 and 40533016), the Ministry of Education of China (106002), and the National Basic Research Program of China (2007CB411801). Q. Fu is supported by NOAA Grant NA08OAR4310725. GCM simulations were done when Y. Hu worked at the Goddard Institute for Space Studies of NASA and
Columbia University. We thank D. L. Hartmann, L. Jaegle, C. B. Leovy, and J. M. Wallace for critical discussion and reading of the manuscript. We also thank J. Zhu for his assistance in part of data analysis.

Edited by: W. E. Asher

\section{References}

Andrews, D. G., Holton, J. R., and Leovy, C. B.: Middle Atmosphere Dynamics, Academic Press, New York, USA, 489 pp., 1987.

Butchart, N. and Scaife, A. A.: Removal of chlorouorocarbons by increased mass exchange between the stratosphere and troposphere in a changing climate, Nature, 410, 799-802, 2001.

Butchart, N., Scaife, A. A., Bourqui, M., et al.: Simulations of anthropogenic change in the strength of the Brewer-Dobson circulation, Clim. Dyn., 27, 727-741, 2006.

Eichelberger, S. J. and Hartmann, D. L.: Changes in the strength of the Brewer-Dobson circulation in a simple AGCM, Geophys. Res. Lett., 32, L15807, doi:10.1029/2005GL022924, 2005.

Fischer, A. M., Shindell, D. T., Winter, B., et al.: Stratospheric winter climate response to ENSO in three chemistry-climate models, Geophys. Res. Lett., 35, L13819, doi:10.1029/2008GL034289, 2008.

Fusco, A. and Salby M. L.: Interannual variations of total ozone and their relationship to variations of planetary wave activity, J. Climate, 12, 1619-1629, 1999.

Hoerling, M. P., Hurrell, J. W., and Xu, T.: Tropical origins for recent North Atlantic climate change, Science, 292, 90-92, 2001.

Hoerling, M. P., Hurrell, J. W., Xu, T., Bates, G. T., and Phillips, A. S.: Twentieth century North Atlantic climate change. Part II: Understanding the effect of Indian Ocean warming, Climate Dyn., 23, 391-405, 2004.

Holton, J. R., Haynes, P. H., McIntyre, M. E., et al.: Stratospheretroposphere exchange, Rev. Geophys., 33, 403-439, 1995.

$\mathrm{Hu}$, Y. and Tung, K.: Interannual and decadal variations of planetary wave activity, stratospheric cooling, and Northern Hemisphere annular mode, J. Clim., 15, 1659-1673, 2002.

Hu, Y. and Tung, K.: Possible ozone-induced long-term changes in planetary wave activity in late winter, J. Clim., 16, 3027-3038, 2003.

Hu, Y., Tung, K., and Liu, J.: A closer comparison of early and late winter atmospheric trends in the Southern Hemisphere, J. Clim., 18, 2924-2936, 2005.

$\mathrm{Hu}$, Y. and Pan, L.: Arctic stratospheric winter warming forced by observed SSTs, Geophys. Res. Lett., 36, L11707, doi:10.1029/2009GL037832, 2009.

Hurrell, J. W. and Loon, H.: A modulation of the atmospheric annual cycle in the Southern Hemisphere, Tellus, 46A, 325-338, 1994.

IPCC: Climate Change 2007: The Physical Science Basis. Contribution of Working Group I to the Fourth Assessment Report of the Intergovernmental Panel on Climate Changes, edited by: Solomon, S., Qin, D., Manning, M., et al., Cambridge University Press, Cambridge, UK, 996 pp., 2007.

Johanson, C. M. and Fu, Q.: Robustness of tropospheric temperature trends from MSU channels 2 and 4, J. Clim., 19, 4234-4242, 2006. 
Johanson, C. M. and Fu, Q.: Antarctic atmospheric temperature trend patterns from satellite observations, Geophys. Res. Lett., 34, L12703, doi:10.1029/2006GL029108, 2007.

Kalnay, E., Kanamitsu, M., Kistler, R. et al.: The NCEP/NCAR 40year reanalysis project. Bull. Am. Meteorol. Soc., 77, 437-471, 1996.

Kistler, R., Kalnay, E., Collins, W., et al.: The NCEP-NCAR 50year reanalysis: Monthly means CD-ROM and documentation, B. Am. Meteor. Soc., 82, 247-267, 2001.

Knutson, T. R. and Manabe, S.: Model assessment of decadal variability and trends in the tropical Pacific ocean, J. Clim., 11, 2273-2296, 1998.

Krüger, K., Naujokat, B., and Labitzke, K.: The Unusual Midwinter Warming in the Southern Hemisphere Stratosphere 2002: A Comparison to Northern Hemisphere Phenomena, J. Atmos. Sci., 62, 603-613, 2005.

Langematz, U., Kunze, M., Krüger, K., Labitzke, K., and Roff, G. L.: Thermal and dynamical changes of the stratosphere since 1979 and their link to ozone and $\mathrm{CO}_{2}$ changes, J. Geophys. Res., 108, 4027, doi:10.1029/2002JD002069, 2003.

Lau, N.-C., Leetmaa, A., and Nath, M. J.: Influences of ENSOinduced Indo-Western Pacific SST anomalies on extratropical atmospheric variability during the boreal summer, J. Clim., 18, 2292-2942, 2005.

Lau, N.-C., Leetmaa, A., and Nath, M. J.: Attribution of atmospheric variations in the 1997-2003 period to SST anomalies in the Pacific and Indian Ocean basins, J. Clim., 19, 3607-3628, 2006.

Lin, P., Fu, Q., Solomon, S., and Wallace, J. M.: Temperature trend patterns in Southern Hemisphere high latitudes: novel indicators of stratospheric change. J. Clim., in press, 2009.

Mears, C. A., Schabel, M. C., and Wentz, F. J.: A reanalysis of the MSU channel 2 tropospheric temperature record, J. Clim., 16, 3650-3664, 2003.

Nishii, K. and Nakamura, H.: Tropospheric influence on the diminished Antarctic ozone hole in September 2002, Geophys. Res. Lett., 31, L16103, doi:10.1029/2004GL019532, 2004.

Ramaswamy, V., Schwarzkopf, M. D., and Randel, W. J.: Fingerprint of ozone depletion in the spatial and temporal pattern of recent lower stratospheric cooling, Nature, 382, 616-618, 1996.
Ramaswamy, V., Chanin, M.-L., Angell, J., et al.: Stratospheric temperature trends: Observations and model simulations, Rev. Geophys., 39, 71-122, 2001.

Randel, W. J. and Wu F.: Cooling of the Arctic and Antarctic polar stratosphere due to ozone depletion, J. Clim., 12, 1467-1479, 1999.

Randel, W.: The seasonal evolution of planetary waves in the Southern Hemisphere stratosphere and troposphere, Q. J. Roy. Meteor. Soc., 114, 1385-1409, 1988.

Rayner, N. A., Parker, D. E., Horton, E. B., et al.: Global analyses of sea surface temperature, sea ice, and night marine air temperature since the late nineteenth century, J. Geophys. Res., 108, 4407, doi:10.1029/2002JD002670, 2003.

Schmidt, G. A., Ruedy, R., Hansen, J. E., et al.: Present day atmospheric simulations using satellite and re-analysis data, J. Clim., 19, 153, 153-192, 2006.

Shindell, D. T. and Schmidt, G. A.: Southern Hemisphere climate response to ozone changes and greenhouse gas increases, Geophys. Res. Lett., 31, L18209, doi:10.1029/2004GL020724, 2004.

Solomon, S.: Stratospheric ozone depletion: a review of concepts and history, Rev. Geophys., 37, 275-316, 1999.

Thompson, D. W. J. and Solomon, S.: Interpretation of recent Southern Hemisphere climate change, Science, 296, 895-899, 2002.

Turner, J., Lachlan-Cope, T. A., Colwell, S. R., Marshall, G. J., and Connolley, W. M.: Significant warming of the Antarctic winter troposphere, Science, 311, 1914-1917, 2006.

Varotsos, C.: The Extraordinary Events of the Major, Sudden Stratospheric Warming, the Diminutive Antarctic Ozone Hole, and its Split in 2002, Environ. Sci. Pollut. Res., 11, 405-411, 2004.

Weatherhead, E. C. and Andersen, S. B.: The search for signs of recovery of the ozone layer, Nature, 441, 39-45, 2006.

WMO (World Meteorological Organization): Scientific Assessment of Ozone Depletion: 2006, Global Ozone Research and Monitoring Project, Report No. 50, Geneva, Switzerland, 572 pp., 2007. 